\title{
Derivation of allometric relationships for radionuclides in marine phyla
}

\author{
J. Vives i Batlle ${ }^{1}$, R.C. Wilson ${ }^{1}$, S.J. Watts ${ }^{1}$, P. McDonald ${ }^{1}$ and A. Craze ${ }^{2}$ \\ ${ }^{1}$ Westlakes Scientific Consulting Ltd., The Princess Royal Building, Westlakes Science \\ and Technology Park, Moor Row, CA24 3LN Cumbria, UK \\ ${ }^{2}$ Nuclear Decommissioning Authority, Herdus House, Westlakes Science and Technology \\ Park, Moor Row, CA24 3HU Cumbria, UK \\ e-mail: jordi.vives@westlakes.ac.uk
}

\begin{abstract}
An allometric scaling approach has been used to calculate biological half-lives of elimination $\left(\mathrm{T}_{\mathrm{B} 1 / 2}\right)$ and concentration factors $(\mathrm{CF})$ for radionuclides in marine biota. Power functions of organism mass are fitted to a biokinetic database for plankton, seaweed, fish, crustaceans and molluscs, using data generated by us, in combination with reviewed data. Scaling of the $\mathrm{CF}$ to $\mathrm{M}^{-0.26 \pm 0.09}$ is observed, compatible at $\pm 1 \sigma$ with metabolic theory predictions that metabolism scales to $\mathrm{M}^{0.75}$. We also observe scaling of $\mathrm{T}_{\mathrm{B} 1 / 2}$ to $\mathrm{M}^{+0.16 \pm 0.03}$, within the previously reported range +0.15 to +0.30 for biota from various environments and, at $< \pm 3 \sigma$, slightly outside turnover rate scaling predictions to $\mathbf{M}^{-0.25}$. The elements for which the CF scales better allometrically are particle seeking, mainly lanthanides and actinides. Association of the independent term of the allometric power function $a$ with the sediment-water partition coefficient $\mathrm{K}_{\mathrm{d}}$ is strongest for these elements, possibly through binding to biological/organic matter. The findings from this study are relevant to extend the range of applicability of our biota dose assessment methodologies where data gaps in transfer exist.
\end{abstract}

\section{INTRODUCTION}

Exchange rate and bioaccumulation of radionuclides in biota are commonly represented by two simple parameters: the biological half-life of elimination $\left(\mathrm{T}_{\mathrm{B} 1 / 2}\right)$ and the concentration factor $(\mathrm{CF})$, which is the activity concentration of a radionuclide in the organism relative to the medium. Reliable $\mathrm{CF}$ and $\mathrm{T}_{\mathrm{B} 1 / 2}$ data are limited to common marine organisms and radionuclides. The present study addresses this problem by presenting an interpolation method based on allometric scaling of radionuclides for plankton, seaweed, fish, crustaceans and molluscs.

Allometric scaling describes the relationship between attributes of living organisms (such as metabolism, ingestion rate, bioaccumulation, etc.) and size, usually expressed as a power law. An example of this is Kleiber's law, in which the whole body metabolic rate is proportional to the mass to the power of +0.75 . In radioecology, allometric scaling refers more specifically to expressing kinetic and transfer parameters, describing the uptake and turnover of radionuclides from the environment to biological organisms, as a power function of their mass. Prior to this study, there has been a scarcity of such functional expressions for marine species, the emphasis to date having been on terrestrial organisms [1-3]. Yet, allometric relationships have been found for the retention of heavy metals by biota in lagoon environments [4] and at least one study reports allometric relationships for ${ }^{210} \mathrm{Po}$ and ${ }^{210} \mathrm{~Pb}$ in marine biota [5].

In the present work, power relationships of the type $Y=a \times M^{b}$ (where $Y$ represents the CF or the long-term component of the $\mathrm{T}_{\mathrm{B} 1 / 2}$ ) were fitted to a biokinetic database. It was expected at the outset of this study that $b$ would be close to the slope of -0.25 expected from theory [6]. It was also anticipated that $a$ would depend on the individual properties of compounds formed by radionuclides in the marine 
environment. Previous work by us [7] had already found allometric formulae for the $\mathrm{CF}$ of $\mathrm{Pu}$ and $\mathrm{Am}$ and $\mathrm{T}_{\mathrm{B} 1 / 2}$ of $\mathrm{Cs}$ and $\mathrm{Tc}$ consistent with previous studies, suggesting that for the $\mathrm{CF} b$ is about -0.25 and for the $\mathrm{T}_{\mathrm{B} 1 / 2}$ it varies between +0.1 and +0.3 (Table 1 ).

Table 1. Allometric relationships for $\mathrm{CF}$ and $\mathrm{T}_{\mathrm{B} 1 / 2}$ from previous work.

\begin{tabular}{|c|c|c|c|c|c|c|c|c|c|}
\hline Parameter & \multicolumn{4}{|c|}{$\log _{10}\left[\mathrm{CF}\left(\mathrm{m}^{3} \mathrm{~kg}^{-1}\right)\right]$} & \multicolumn{5}{|c|}{$\log _{10}\left[T_{B 1 / 2}(d)\right]$} \\
\hline & $\mathbf{P u}^{\mathbf{a}}[7]$ & $\mathbf{A m}^{\mathbf{a}}[7]$ & Po [5] & $\mathbf{P b}[5]$ & $\mathbf{C s}^{\mathbf{a}}[7]$ & $\mathrm{Cs}^{\mathrm{d}}$ & $\mathbf{S r}^{\mathbf{b}}[2]$ & $\mathbf{I}^{\mathbf{b}}[2]$ & $\mathbf{T c}^{\mathbf{a}}$ [7] \\
\hline $\log _{10} a$ & -0.74 & -0.64 & $\mathrm{n} / \mathrm{a}$ & $\mathrm{n} / \mathrm{a}$ & 1.72 & 1.17 & 2.81 & 1.22 & 2.00 \\
\hline $\mathrm{b}$ & -0.30 & -0.28 & -0.24 & -0.22 & 0.16 & 0.21 & 0.26 & 0.13 & 0.15 \\
\hline $\mathrm{r}^{2}$ & 0.76 & 0.76 & $\mathrm{n} / \mathrm{a}$ & $\mathrm{n} / \mathrm{a}$ & 0.92 & $\mathrm{n} / \mathrm{a}$ & $\mathrm{n} / \mathrm{a}$ & $\mathrm{n} / \mathrm{a}$ & 0.74 \\
\hline $\mathrm{p}$ & 0.001 & 0.001 & $\mathrm{n} / \mathrm{a}$ & $\mathrm{n} / \mathrm{a}$ & 0.04 & $\mathrm{n} / \mathrm{a}$ & $\mathrm{n} / \mathrm{a}$ & $\mathrm{n} / \mathrm{a}$ & 0.03 \\
\hline $\mathrm{N}$ & 10 & 10 & $\mathrm{n} / \mathrm{a}$ & $\mathrm{n} / \mathrm{a}$ & 4 & $\mathrm{n} / \mathrm{a}$ & $\mathrm{n} / \mathrm{a}$ & $\mathrm{n} / \mathrm{a}$ & 6 \\
\hline
\end{tabular}

${ }^{\mathrm{a}}$ Converted from $\mathrm{y}=\mathrm{a} \times \mathrm{V}^{\mathrm{b}}$ with $\mathrm{V}$ in $\mathrm{m}^{3}$ to $=\mathrm{a} \times \mathrm{M}^{\mathrm{b}}$ with $\mathrm{M}$ in $\mathrm{kg}$ using a density of $10^{3} \mathrm{~kg} \mathrm{~m}^{-3}$.

${ }^{b}$ Taken from [1], in turn quoting [8,9]. Only the latter gives the units for the $\mathrm{T}_{\mathrm{B} 1 / 2}$ in days, as shown here.

\section{MATERIALS AND METHODS}

A dataset of biokinetic parameters for $\mathrm{Tc}, \mathrm{I}, \mathrm{Cs}, \mathrm{Pu}$ and $\mathrm{Am}$ in fish, crustaceans, molluscs, macroalgae/seaweed and plankton $[7,10]$ was used in this study. To this was added data for 29 additional elements using tabulated data [11] where available. For the $\mathrm{T}_{\mathrm{B} 1 / 2}$ we sourced data for $\mathrm{Cm}$ and Po in winkles [12, 13], Ag, Co, Eu, Mn, Zn [14], Mn and Co [15] in macrophytes, C in macrophytes and molluscs [16] and Se in fish, crustaceans and molluscs [17, 18].

We calculated the linear regression parameters $\log _{10} \mathrm{a}$ and $\mathrm{b}$ for the expression $\log _{10} Y=\log _{10} a+$ $b \times \log _{10} M$, where $Y$ can be the $\mathrm{CF}$ or the $\mathrm{T}_{\mathrm{B} 1 / 2}$ and $\mathrm{M}$ is the organism mass. Standard errors (SE) in $\log _{10} \mathrm{a}$ and $\mathrm{b}$ were derived using statistical error propagation [19]. We also calculated the coefficient of determination $\mathrm{r}^{2}$ and the $\mathrm{p}$-value of the two-tailed Student T-test. To discriminate statistically significant relationships we used the triple criteria $\mathrm{r}^{2}>0.7, \mathrm{p}<0.05, \mathrm{~N}>2$.

\section{RESULTS}

Of the 34 independent regressions calculated for the $\mathrm{CF}$, there were 8 for which allometric relationships satisfying the triple criteria for significance were found (Table 2). What these elements have in common (with the exception of $\mathrm{Ra}$ and $\mathrm{Ru}$ ) is being lanthanides or actinides. The fitted parameters are consistent with previous work [7].

Table 2. Statistically significant allometric relationships for $\mathrm{CF}$ and $\mathrm{T}_{\mathrm{B} 1 / 2}$ from the present work.

\begin{tabular}{|l|c|c|c|c|c|c|c|c|c|c|c|c|}
\hline Parameter & $\log _{\mathbf{1 0}}\left[\mathbf{C F}\left(\mathbf{m}^{\mathbf{3}} \mathbf{k g}^{-\mathbf{1}}\right)\right]$ & $\mathbf{9}$ & \multicolumn{3}{|c|}{$\log _{\mathbf{1 0}}\left[\mathbf{T}_{\mathbf{B} \mathbf{2} \mathbf{2}}(\mathbf{d})\right]$} \\
\hline & $\mathbf{R u}$ & $\mathbf{C e}$ & $\mathbf{P m} / \mathbf{E u}$ & $\mathbf{R a}$ & $\mathbf{T h}$ & $\mathbf{P u}$ & $\mathbf{A m}$ & $\mathbf{C m}$ & $\mathbf{T c}$ & $\mathbf{C s}$ & $\mathbf{P u}$ & $\mathbf{A m}$ \\
\hline $\log _{10} \mathrm{a}$ & -1.54 & -0.33 & 0.19 & -1.07 & -0.25 & -0.68 & -0.60 & -0.44 & 1.99 & 1.73 & 2.80 & 2.40 \\
\hline $\mathrm{b}$ & -0.46 & -0.25 & -0.18 & -0.11 & -0.27 & -0.30 & -0.28 & -0.27 & 0.15 & 0.17 & 0.20 & 0.13 \\
\hline $\mathrm{r}^{2}$ & 0.75 & 0.72 & 0.72 & 0.79 & 0.89 & 0.80 & 0.78 & 0.85 & 0.72 & 0.92 & 0.91 & 0.76 \\
\hline $\mathrm{SE}\left(\log _{10} \mathrm{a}\right)$ & 0.37 & 0.22 & 0.17 & 0.08 & 0.14 & 0.22 & 0.21 & 0.17 & 0.20 & 0.08 & 0.39 & 0.22 \\
\hline $\mathrm{SE}(\mathrm{b})$ & 0.10 & 0.06 & 0.04 & 0.02 & 0.04 & 0.06 & 0.06 & 0.04 & 0.05 & 0.04 & 0.06 & 0.04 \\
\hline $\mathrm{p}$ & 0.002 & 0.004 & 0.004 & 0.001 & 0.0002 & 0.001 & 0.002 & 0.0004 & 0.03 & 0.04 & 0.2 & 0.05 \\
\hline $\mathrm{N}$ & 9 & 9 & 9 & 9 & 9 & 9 & 9 & 9 & 6 & 4 & 3 & 5 \\
\hline
\end{tabular}

Additionally, five other regressions for the $\mathrm{CF}$ of $\mathrm{Mn}, \mathrm{Zr}$, Po, Ac and $\mathrm{Pa}$ (all elements with a high sediment-water partition coefficient, or $\mathrm{K}_{\mathrm{d}}$ ) approach potential statistical significance $(\mathrm{T}$-test $\mathrm{p}<0.05)$ 
Table 3. Allometric relationships for CF potentially approaching statistical significance.

\begin{tabular}{|l|c|c|c|c|c|}
\hline Parameter & \multicolumn{5}{|c|}{$\log _{\mathbf{1 0}}\left[\mathbf{C F}\left(\mathbf{m}^{\mathbf{3}} \mathbf{k g}^{-\mathbf{1}}\right)\right]$} \\
\hline & $\mathbf{M n}$ & $\mathbf{Z r}$ & $\mathbf{P o}$ & $\mathbf{A c}$ & $\mathbf{P a}$ \\
\hline $\log _{10} \mathrm{a}$ & 0.64 & -0.57 & 0.74 & -0.42 & -1.24 \\
\hline $\mathrm{b}$ & -0.13 & -0.30 & -0.17 & -0.18 & -0.17 \\
\hline $\mathrm{r}^{2}$ & 0.46 & 0.68 & 0.64 & 0.58 & 0.53 \\
\hline SE(Log $\left.{ }_{10} \mathrm{a}\right)$ & 0.21 & 0.30 & 0.19 & 0.22 & 0.23 \\
\hline SE(b) & 0.05 & 0.08 & 0.05 & 0.06 & 0.06 \\
\hline $\mathrm{p}$ & 0.04 & 0.007 & 0.01 & 0.02 & 0.03 \\
\hline $\mathrm{N}$ & 9 & 9 & 9 & 9 & 9 \\
\hline
\end{tabular}

and may therefore be usable, although in this case $0.4<\mathrm{r}^{2}<0.7$, indicating a poorer goodness of fit. (Table 3).

For the data from Table 2 a mean slope of $-0.26 \pm 0.09$ is supported, a confirmation of allometric scaling to a quartile power of the mass for marine biota, as predicted theoretically. Tritium is a special exception to this, as the $\mathrm{CF}$ for ${ }^{3} \mathrm{H}$ is defined as being $10^{-3} \mathrm{~m}^{3} \mathrm{~kg}^{-1}$ for all organisms. For the five additional elements approaching potential statistical significance a mean slope of $-0.19 \pm 0.06$ is found. This is lower but still statistically consistent at $\pm 1 \sigma$ with a scaling slope of 0.25 .

The intercept $\log _{10}$ a in Table 2 ranges from -1.5 to +0.2 , which implies a two order of magnitude range of variation in $a$. This important variability is thought to relate to the physico-chemical speciation of different radioelements in seawater. In an attempt to verify this hypothesis we plotted $\log _{10}$ a as a function of various parameters including atomic mass, electronegativity, ionic radius and oxidation state, with negative results.

Noticing a general tendency for the more sediment-seeking nuclides to register the highest values, we uncovered a statistically significant linear trend between $\log _{10}$ a and $\log _{10} \mathrm{~K}_{\mathrm{d}}$. The goodness of fit and the statistical significance of this trend improve greatly with the removal of $\mathrm{Ru}, \mathrm{Eu}$ and $\mathrm{Pm}$ (Figure 1). With the inclusion of $\mathrm{Mn}, \mathrm{Zr}, \mathrm{Po}, \mathrm{Ac}$ and $\mathrm{Pa}$ the trend becomes weakened $\log _{10} \mathrm{a}=$ $\left.0.38 \times \log _{10} \mathrm{~K}_{\mathrm{d}}-1.6, \mathrm{r}^{2}=0.50, \mathrm{~N}=13\right)$ but statistical significance remains strong $(\mathrm{p}=0.007)$. The additional elements tend not to fit the linear trend within $\pm 1 \sigma$.
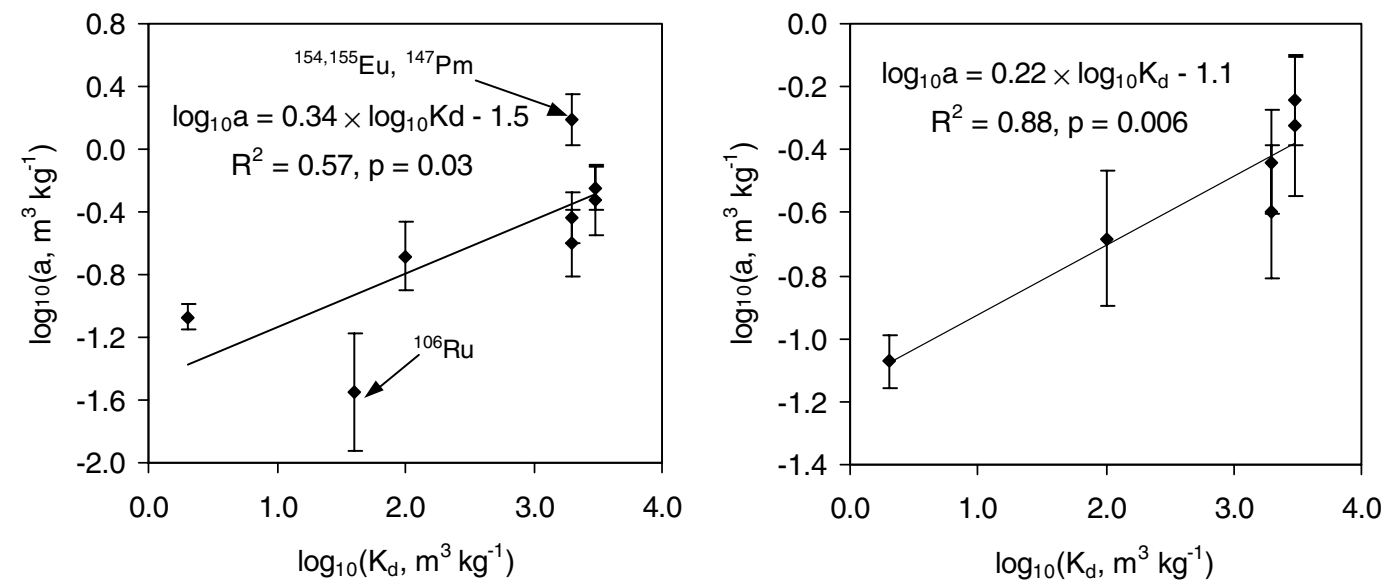

Figure 1. Linear trend between $\log _{10}$ a for the $\mathrm{CF}$ and $\log _{10} \mathrm{~K}_{\mathrm{d}}$, both with (left) and without (right) $\mathrm{Ru}, \mathrm{Eu}$ and $\mathrm{Pm}$. Error bars represent the standard error of $\log _{10}$ a.

An association between the $C F$ and the $K_{d}$ has been previously suggested [20], noting that this relationship works only for radionuclides in a cationic form. Our work also confirms this, as the majority 
of radionuclides correlating with $\mathrm{K}_{\mathrm{d}}$ are cations and the few nuclides likely to be present as anions (such as $\mathrm{Ru}$ ) tend to be outliers in Figure 1.

In addition to the two $\mathrm{T}_{\mathrm{B} 1 / 2}$ relationships for $\mathrm{Tc}$ and $\mathrm{Cs}$ identified before [7], the current study has uncovered a statistically significant formula for Am and a potentially significant one for Pu (Table 2). In the latter case, $\mathrm{N}=3$ and with such few data a p-value of 0.2 is generated, although $\mathrm{r}^{2}=0.9$ and the allometric parameters are consistent with those found for Am.

Taken together, these three relationships support an intercept of $+0.16 \pm 0.03$. The intercept ranges from 1.73 for $\mathrm{Cs}$ and 1.99 for Tc (more predominantly conservative radionuclides) to 2.40 for Am and 2.80 for $\mathrm{Pu}$ (both particle-seeking, non-conservative nuclides).

The standard errors for the intercept and slope given in Table $2\left(\mathrm{SE}_{\operatorname{loga}}\right.$ and $\left.\mathrm{SE}_{\mathrm{b}}\right)$ can be used to perform uncertainty estimations in the $\mathrm{CF}$ and $\mathrm{T}_{\mathrm{B} 1 / 2}$ when allometric equations are used in predictive mode. For this it is only necessary to use the simple maximising error propagation formula:

$$
\frac{\Delta y}{y \times \ln (10)}=\Delta \log _{10}(a)+\Delta b \times\left|\log _{10}(M)\right|
$$

For most species the absolute value of $\log (\mathrm{M})$ ranges between 1 to 2 except for phytoplankton (10) and zooplankton (4). According to this, on the basis of statistical uncertainties, $\mathrm{CF}$ and $\mathrm{T}_{\mathrm{B} 1 / 2}$ predictions would range from 20-140\% for macroscopic animals and plants and 70-320\% for plankton. In practice, the allometric formulae reproduce the $\mathrm{CF}$ quite well, with $70 \%$ of the values within a factor of two and only $8 \%$ of the values within a factor of five or more. For the $\mathrm{T}_{\mathrm{B} 1 / 2}$ the percentage is $90 \%$, with no values in excess of a factor of four difference.

\section{DISCUSSION}

A consistent picture seems to emerge from our results. The elements that scale allometrically with a quartile power of the mass in marine biota $\left(\mathrm{Ru}, \mathrm{Ce}, \mathrm{Pm} / \mathrm{Eu}, \mathrm{Ra}, \mathrm{Th}, \mathrm{Pu}, \mathrm{Am}\right.$ and $\mathrm{Cm}$ ) have high $\mathrm{K}_{\mathrm{d}} \mathrm{s}$, with a significant proportion being lanthanides and actinides. The additional elements for which allometric scaling of the $\mathrm{CF}$ approaches significance ( $\mathrm{Mn}, \mathrm{Zr}$, Po, Ac and $\mathrm{Pa}$ ), also tend to exhibit higher particle reactivity.

Association of $a$ with the $\mathrm{K}_{\mathrm{d}}$ suggests the former being highest for particle-seeking elements, most likely binding to biological/organic matter. We hypothesise that, for the elements found to correlate allometrically, the driving uptake process may be ingestion, with the scaling behaviour observed being a consequence of the physics and geometry of energy distribution networks within organisms. Metabolic theory predicts that the whole body metabolism scales to $\mathbf{M}^{+0.75}$ (Kleiber's Law) $[6,21]$. This is what appears to drive the ingestion rate scaling to $\mathbf{M}^{+0.75}$ predicted for land animals [1].

The observed scaling of the $\mathrm{CF}$ to $\mathrm{M}^{-0.25}$ is compatible with this metabolic explanation, as the $\mathrm{CF}$ is the activity concentration in the organism (activity $\times \mathrm{M}^{-1}$ ) relative to the medium. In other words, metabolically driven allometry of the ingestion rate could be responsible for the scaling behaviour in the organisms and radionuclides considered, as previously suggested in studies of the uptake of $\mathrm{Cd}$ and $\mathrm{Zn}$ by marine invertebrates [22]. However, for some elements, the process could also be surface-area driven (e.g. passive sorption of radionuclides on body surfaces, such as mollusc shells). In this case, surface area dependence on mass to the power of ${ }^{2} / 3$ would result in the $C F$ scaling to $\mathrm{M}^{-0.33}$ instead of $\mathrm{M}^{-0.25}$. Increasing the statistical power of this study to discriminate $b=-0.25$ from -0.33 on a radionuclide to radionuclide basis is, therefore, a reasonable proposal for future investigation.

The observed scaling of $\mathrm{T}_{\mathrm{B} 1 / 2}$ to the power of +0.16 , based on limited data, is compatible with the range +0.15 to +0.30 reported elsewhere [1]. If potential statistical compatibility with +0.25 at $\pm 3 \sigma$ is further confirmed, this would be consistent with the prediction that turnover rate constants (proportional to $\mathrm{T}_{\mathrm{B} 1 / 2}^{-1}$ ) generally decrease with mass at an exponent of -0.25 [23]. It is also possible that for some radionuclides (e.g. strontium) $\mathrm{T}_{\mathrm{B} 1 / 2}$ is not merely associated with the metabolic turnover rate, but other 
factors such as stable element concentrations influence it [24], thus deviating from a simple $\mathrm{M}^{-0.25}$ scaling relationship.

A simple statistical calculation (Eq. 1) suggests that standard errors in the $\mathrm{CF}$ and $\mathrm{T}_{\mathrm{B} 1 / 2}$ are rarely one order of magnitude greater than those variables. However, the propagation of errors in individual transfer parameters is not included in this calculation. An outstanding question is, therefore: Adjusting for size, how does the same $\mathrm{CF}$ or $\mathrm{T}_{\mathrm{B} 1 / 2}$ compare in two different organisms? Although allometric modelling has provided accurate predictions of biological growth and physiological function in both human and animal studies, the principal source of uncertainty in radiological assessments continues to be the variability in the transfer parameters themselves and the uncertainty in the allometric relationships arising thereof. Thus, our application of the kinetic/allometric method to marine organisms should be regarded as a broad generalisation until such time as it is integrated with transfer parameter distribution calculations.

\section{CONCLUSIONS}

Our evidence supports the conclusion that $\mathrm{CFs}$ and $\mathrm{T}_{\mathrm{B} 1 / 2} \mathrm{~s}$ for the marine organisms studied herein scale to quartile powers of organism mass, similar to warm-blooded species in the terrestrial environment, at least for the lanthanides and actinides. It is not difficult to relate the relatively simple analysis presented here with theoretically derived allometric relationships for the metabolic rate. However, for some elements, simple surface-exchange allometry cannot be excluded at this stage.

The work presented here suggests a method to address data gaps in radionuclide transfer for marine biota, based on allometry. Such a method still requires detailed study of the effects of uncertainty in transfer parameters, particularly the $\mathrm{CF}$, which is known to have large intra-species variability. Moreover, additional uncertainty in transfer arises from the fact that environmental compartments are rarely in isotopic equilibrium.

As a first effort to address these problems, the present allometric analysis is being combined with biokinetic modelling in a dynamic model for the assessment of radiological exposure to marine biota [10]. The present study has the potential to bridge data gaps and widen the range of applicability for this model, signalling the way for new investigations [25].

\section{References}

[1] USDoE (U.S. Department of Energy) DOE Standard: A Graded Approach for Evaluating Radiation Doses to Aquatic and Terrestrial Biota. Module 3: Methods Derivation. DOE-STD1153-2002, Washington DC (2002) 58 pp.

[2] Higley K.A., Domotor S.L. and Antonio E.J. A kinetic-allometric approach to predicting tissue radionuclide concentrations for biota, J. Environ. Radioactiv. 66 (2003) 61-74.

[3] Beresford N.A., Broadley M.R., Howard B.J., Barnett C.L. and White P.J. Estimating radionuclide transfer to wild species - data requirements and availability for terrestrial ecosystems. J. Radiol. Prot. 24 (4A) (2004) A89-A103.

[4] Hédouin L., Metian M., Teyssié J.-L., Fowler S.W., Fichez R. and M. Warnau. Allometric relationships in the bioconcentration of heavy metals by the edible tropical clam Gafrarium tumidum. Sci. Total Environ. 366(1) (2006) 154-163.

[5] Cherry R.D. and Heyraud M. Polonium-210 and lead-210 in marine organisms: allometric relationships and their significance. In: Radionuclides in the Study of Marine Processes. PJ Kershaw, DS Woodhead, editors. Elsevier Applied Science, London \& New York (1991) 309-318.

[6] West G.B., Brown J.H. and Enquist B.J. A general model for the origin of allometric scaling laws in biology. Science 276 (1997) 122-126. 
[7] Vives i Batlle J., Wilson R.C. and McDonald P. Allometric methodology for the calculation of biokinetic parameters for marine biota. Sci. Total. Environ. 388 (1-3) (2007) 256 - 269.

[8] Whicker F.W and Schultz V. Radioecology: Nuclear Energy and the Environment. Vols. I and II. Boca Raton, Florida: CRC Press (1982).

[9] Kitchings T., DiGregorio D. and Van Voris P. A review of the ecological parameters of radionuclide turnover in vertebrate food chains. In: Cushing, C.E. (Ed.), Radioecology and Energy Resources. Dowden, Hutchinson \& Ross, Stroudsburg, PA (1976) pp. 304-313.

[10] Vives i Batlle J., Wilson R.C., Watts S.J., Jones S.R., McDonald P. and Vives-Lynch S. Dynamic model for the assessment of radiological exposure to marine biota. J. Environ. Radioactiv. (2008). doi:10.1016/j.jenvrad.2007.11.002.

[11] International Atomic Energy Agency. Sediment Distribution Coefficients and Concentration Factors for Biota in the Marine Environment. Technical Reports Series No. 422, Vienna. IAEA STI/DOC/010/422 (2004).

[12] Swift D.J. A laboratory study of ${ }^{239,240} \mathrm{Pu},{ }^{241} \mathrm{Am}$ and ${ }^{243,244} \mathrm{Cm}$ depuration by edible winkles (Littorina littorea L.) from the Cumbrian Coast (NE Irish Sea) radiolabelled by Sellafield discharges. J. Environ. Radioactiv. 27 (1995) 13-33.

[13] Swift D.J., Smith D.L., Allington D.J. and Winpenny K. A laboratory and field study of ${ }^{210}$ Po depuration by edible winkles (Littorina littorea L.) from the Cumbrian Coast (north-eastern Irish Sea). J. Environ. Radioactiv. 26 (2) (1995) 119-133.

[14] Boisson F., Hutchins D.A., Fowler S.W., Fisher N.S. and Teyssie J-L. Influence of temperature on the accumulation and retention of 11 radionuclides by the marine alga Fucus vesiculosus (L.). Mar. Pollut. Bull. 35(7-12) (1997) 313-321.

[15] Carlson L. Uptake and release of ${ }^{54} \mathrm{Mn}$ and ${ }^{60} \mathrm{Co}$ in Fucus vesiculosus L. and its epiphytes. J. Environ. Radioact. 22(1) (1994) 29-41.

[16] Fiévet B., Voiseux C., Rozet M., Masson M. and Bailly du Bois P. Transfer of radiocarbon liquid releases from the AREVA La Hague spent fuel reprocessing plant in the English Channel. J. Environ. Radioactiv. 90(3) (2006) 173-196.

[17] Alquezar R., Twining J.R. and Markich S.J. Uptake and loss of ${ }^{109} \mathrm{Cd}$ and ${ }^{75} \mathrm{Se}$ in estuarine macroinvertebrates. Chemosphere 67 (2007) 1202-1210.

[18] Alquezar R., Markich S.J. and Twining J.R. Comparative accumulation of ${ }^{109} \mathrm{Cd}$ and ${ }^{75} \mathrm{Se}$ from water and food by an estuarine fish (Tetractenos glaber). J. Environ. Radioactiv. 99 (2008) 167 180.

[19] Weisstein E.W. Least Squares Fitting. MathWorld-A Wolfram Web Resource (2008). http:// mathworld.wolfram.com/LeastSquaresFitting.html

[20] Copplestone D., Wood M., Bielby S., Jones S.R., Vives J. and Beresford N.A. Habitats regulations for Stage 3 assessments: radioactive substances authorisations. Environment Agency R\&D Technical Report P3-101/SP1A (2003) 104 pp.

[21] McMahon T.A. Size and shape in biology. Science 179 (1973) 1201-1204.

[22] Pan K. and Wang W-X. Allometry of cadmium and zinc concentrations and bioaccumulation in the scallop Chlamys nobilis. Mar. Ecol. Prog. Ser. Prepress Abstract (2008). doi: 10.3354/meps07451.

[23] Hendriks A.J. The power of size: A meta-analysis reveals consistency of allometric regressions. Ecol. Modelling 205(1-2) (2007) 196-208.

[24] Beresford, N.A. Biological half-life. EURANOS (CAT1)-TN(06)-04 Deliverable D6C1R1 Supplementary Documents (2005). http://www.strategy-ec.org.uk/EURANOS_D6C1R1/ Euranosdatasheets/associateddocs/biological\%20half .pdf .

[25] Watts S.J., Vives i Batlle J., Wilson R.C., Jones S.R. and McDonald P. Dynamic modelling for the assessment of radiation impacts on biota and man using Excel VBA and related extensions of the ERICA assessment methodology. In: Proc. International conference on radioecology and environmental radioactivity, 15 - 20 June 2008, Bergen, Norway. 